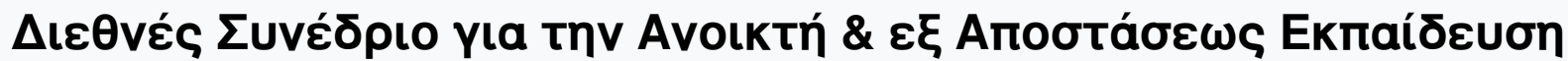

Tón. 8, Ap. 4B (2015)

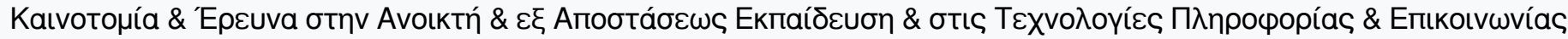

| Пракuiká

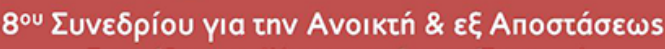

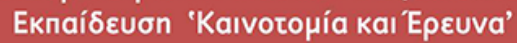

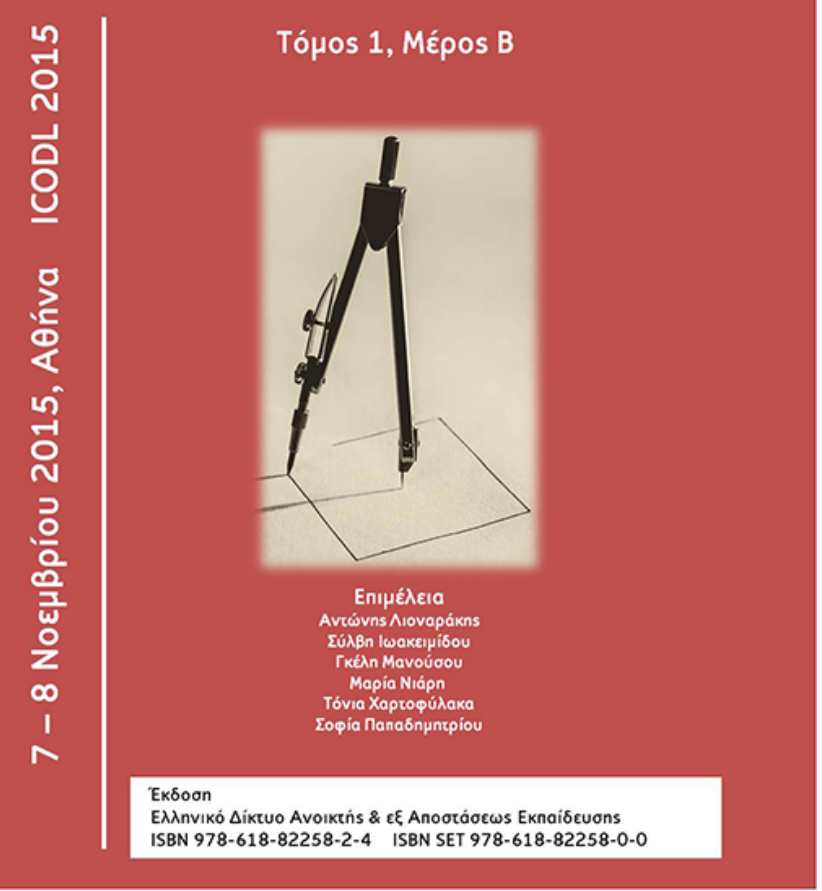

The What, Why, Which and How of Digital Learning Role Profiles and Training Guidelines

Adamantia Spanaka, Clive Shepherd, Achilles Kameas

doi: $10.12681 /$ icodll.82 


\title{
The What, Why, Which and How of Digital Learning Role Profiles and Training Guidelines
}

\author{
Adamantia Spanaka \\ Hellenic Open University \\ Greece \\ Adjunct Professor \\ madspa@otenet.gr
}

\author{
Clive Shepherd \\ Fastrak \\ UK \\ Consultant learning technologist \\ clives@ fastrak-consulting.co.uk
}

\author{
Achilles Kameas \\ Hellenic Open University \\ Greece \\ Assistant Professor \\ kameas@eap.gr
}

\begin{abstract}
What we mean by digital learning? Why digital learning matters? Which are the main skills that will help to boost the employability of digital learning professionals? How can we structure a good training course? Based on these questions, the eVirtue project (http://groupspaces.com/eVirtue/), funded by the European Commission in the context of LifeLong Learning Programme, conducted an in-depth research of the competences and skills necessary for trainers so that they meet the requirements of emerging, technology-based training job roles. In addition, a set of guidelines to design trainings that would provide qualifications that match the specifications of each of the new role roles has been developed, to be used by Vocational Education and Training (VET) providers, employers and employees. These are based on a thorough review of current training and educational offers and present in a practical way a complete structure of learning units that should be designed by VET organisations who are active in the field of e-learning professions.
\end{abstract}

Key words: digital learing, role profiles, training guidelines.

\section{Strictly for beginners}

Digital learning is a term that describes the application of computer hardware and software, and computer networks such as the Internet, to any aspect of teaching and learning (Graham, 2004; Huggett, 2013). Digital learning frees the learner from the constraints of time and space, providing access to billions of fellow learners and practically limitless educational content (MacKeogh \& Fox, 2009; Yilmaz, 2015). The term 'digital learning' is equivalent in most respects to terms such as 'virtual learning', 'online learning' and 'e-learning'.

E-learning has the potential to dramatically reduce the costs of vocational learning as well as providing access to learning for many more people across the EU and the rest of the world (Krug, 2006; Shepherd, 2015); this at a time when economic success is so closely tied to the knowledge and skills of working people.

\section{Forms of digital learning}

Digital learning, within the context of vocational education and training, comes in many varieties (Shepherd, 2015:

- Interactive, self-study lessons delivered online, and taking various forms including tutorials, practice drills, scenarios, games and simulations. This is the form of 
digital learning that is perhaps most familiar in a corporate context and is often referred to in this context as e-learning.

- Non-interactive digital content, including videos, podcasts, web articles, infographics, slide shows, software demonstrations, PDF files, e-books and so on.

- Live online sessions delivering a virtual classroom experience with the aid of web conferencing software. Sessions that cater for larger numbers of participants are typically called 'webinars'.

- Distance learning courses, which may make use of the content and live sessions described above, but also allow for on-going collaboration between students and with tutors. These courses may be entirely online or blended to include face-toface elements. Although most of these courses are relatively small, we are now a rapid expansion in MOOCS (Massive Open Online Courses) that may include tens of thousands of students.

- Performance support systems, which provide employees with just-in-time access to the information they need to carry out their jobs. These systems are particularly useful when they are made available on mobile devices.

- Informal learning, outside the scope of formal courses, using tools such as social networks, wikis, blogs, search engines, video content libraries and so on.

Clearly these varieties of digital learning can be applied independently or together in many ways, depending on the context. Similarly, the roles undertaken by professionals working with learning technologies can be combined in all sorts of ways.

\section{The e-Virtue project}

The e-Virtue project was established to help make sure we have the skills available in Europe to take advantage of the opportunities provided by learning technologies. EVirtue aims to identify the competences and skills required to fulfil various roles in digital learning, not just by full-time specialists but all learning professionals. The role profiles identified by the project have been mapped to the European Qualifications Framework (EQF) and the European e-Competences Framework (e-CF). Furthermore, e-Virtue has developed a set of training guidelines, including a catalogue of learning outcomes.

The role profiles and training guidelines will help to boost the employability of digital learning professionals, reducing the mismatches between labour demand and supply and enhancing the mobility of workers (Spanaka \& Kameas, 2015).

\section{The six digital learning role profiles}

In the course of the e-Virtue project, we have identified six roles, which we believe best describe the sorts of tasks that learning professionals have to undertake to take advantage of learning technologies. Remember these are role profiles not job descriptions - only in some cases will they be carried out by anyone on a full-time basis. There will be many times when several of these roles are combined into a one job position, often in conjunction with all sorts of roles that are not connected with learning technology.

1. Architecting an e-learning strategy: The digital learning architect, also known as the e-learning manager or learning technologies manager, is responsible for the development and implementation of an organisation's strategy for the use of learning technologies, as derived from the business strategy. This role may be undertaken by a learning technologies specialist, by a manager with overall 
responsibility for learning, by external learning consultants or some combination of these.

2. Designing blended learning solutions: The professional role of designing blended learning solutions, is performed by a professional, also known as learning solutions designer or learning consultant, bended learning designer or even learning programme designer, who is responsible for creating the top-level design for a learning intervention, whether or not the decision is ultimately taken to include an e-learning element. These skills must be in place if e-learning is to be applied appropriately.

3. Developing e-learning content - full-time specialist role: The professional role of developing e-learning content (full time specialist), is performed by a specialist -also known as instructional designer, web content developer, multimedia developer or e-learning producer- who designs and/or develops digital learning content in all its forms, i.e. tutorials, simulations, games, assessments, videos, podcasts, troubleshooting guides and simple reference material. S/He undertakes sophisticated projects that require the skills only normally found in multidisciplinary teams including creative, technical and content specialists. This will normally be a full-time position.

4. Developing e-learning content (one part of a broader teaching/training role): The developing e-learning content (part-time), also known as an instructional designer, is a teacher/trainer who designs and/or develops simpler forms of digital learning content including reference materials, slides, assessments, screencasts, interview videos, podcasts, etc. This role will normally be just one aspect of a general teaching/training role. In some cases, the role may also be undertaken by a subject specialist who is not a learning professional. An essential aspect of this role is that the person is likely to be designing and developing this content to support the teaching or training for which they are responsible, in the way that a teacher creates slides or handouts for their classes. This can be contrasted with a full-time content developer who could create content for any subject or purpose and who has no teaching or training responsibilities.

5. Tutoring online: The professional role of online tutoring Is performed by a specialist, also known as virtual/online facilitator/moderator/programme lead or etutor, who is responsible for ensuring the successful delivery of extended online and blended distance-learning programmes and to support students as they engage in these programmes. Tutoring online may also provide support to those learning informally on-the-job, outside the scope of a formal programme, often through content curation. Furthermore, a professional in this role may play some role in the design of online activities and assignments for individuals and groups that take place within a programme. Note that one of the roles of tutoring online may be to act as a virtual classroom facilitator. However, not all virtual classroom sessions' facilitators are also tutoring online.

6. Facilitating virtual classroom sessions: The professional role facilitating virtual classroom sessions is performed by a specialist, also known as virtual/online classroom teacher/trainer/instructor/facilitator is a teacher/trainer who designs and delivers real-time group sessions using web conferencing tools (these are also sometimes called 'webinars'). These sessions are the online equivalent of sessions held in physical lecture rooms and classrooms and could take the form of lectures, seminars, workshops, coaching or instruction. This role will normally be just one aspect of a general teaching/training role or will be undertaken by a subject expert. Some professionals facilitating virtual classroom sessions may also take on the 
broader role of tutoring online, in which they have overall responsibility for overseeing and delivering all aspects of an online learning programme.

\section{The Training Guidelines}

The main objective of Training Guidelines (TG) is to present, in a practical way (Bell, \& Kozlowski, 2008) a structure of learning units that should be trained by Vocational Education and Training (VET) organisations in the field of "Virtual Learning professions". In this sense, training guidelines are designed to guide those involved in training in a wide variety of settings - training centres, companies, community locations and other training sites. Thus, Training Guidelines present relevant information for all the stakeholders interested in finding out which knowledge, skills and competences are required to succeed in the labour marker in the field of Virtual Learning services across the EU. More specifically, the present Training Guidelines are mainly addressed to:

80 Vocational Education and Training (VET) organizations which are interested in adapting their training offer to the market needs, in order to fulfil the constant and increasing demand of qualifying virtual learning professionals at the European level. As the role profiles for virtual learning professions reflect the market needs, they, in conjunction with the Training Guidelines, will enable VET institutions tailor their courses according to them.

80 Employers and/or Human Resources Managers, in particular of SMEs, developing in-house training modules. Both the developed role profiles for virtual learning professions and the Training Guidelines will enable these professionals determine, whether (foreign) job applicants and employees have the knowledge, skills and competencies required at European level in the field of virtual learning.

8o (Potential) Employees, in particular of SMEs, identifying personal training needs. Both the role profiles for Virtual Learning professions and the Training Guidelines will support (potential) employees gain insight into knowledge, skills and competencies required at the European level in the field of Virtual Learning, enabling them to determine, whether they are sufficiently skilled.

The difficulty with designing any type of training guide is that it can never be all things to all users (Keppel, et al, 2003). At the same time, it must be useful to all its readers.

For this reason, this manual of training guidelines:

- does not provide a step-by-step method for determining learning units,

- is not a series of recipes,

- is not a fill-in-the-blank-type guide.

Instead, in these training guidelines we aim to describe some approaches to designing training:

- offering some ideas on the process of developing a learning unit

- showing you some examples of how it can be done.

The manual of Training Guidelines is organized into three sections:

Section 1 provides an overview of the manual and of the basic principles underlying facilitating learning events. These principles cover key areas that all facilitators should keep in mind when undertaking any training programme. This Section 1 is basically an outline of all the 'what, who, and how' details of the training for use by trainers.

Section 2, the most extensive section, consists of training guidelines for each of the six role profiles, like mapping out a road trip or creating a journey. For each role profile a description of the specific role is provided along with a presentation of the suggested learning units structured from an output-oriented perspective is offered, which means a specification of learning outcomes as recommended by the European Qualification Framework. Thus, each learning unit suggests the learning outcomes that participants 
will be able to achieve as a result of completing the training, in order to be qualified to assume virtual learning-related positions in the European labour market. Furthermore, each role profile unit provides guidelines on which training methods, activities and additional reading may be used so that participants meet the learning objectives most effectively.

Finally, Section 3 should begin to create an awareness of the European standards for transparency and comparability of vocational education and training, which facilitate professional mobility within Europe and on which these Training Guidelines are based on. So, it presents the European Qualification Framework (EQF), the e-Competence Framework (eCF), the European Credit System for Vocational Education the European Quality Assurance in Vocational Education and Training (EQAVET), and Training (ECVET) systems. In addition, it describes the e-Jobs Observatory, as the main initiative for ensuring quality, harmonization and standardization of vocational training for these six role profiles at the European level and explains why the Virtual Learning role profiles are in line with the standards proposed by the e-Jobs Observatory.

At the end, the training guidelines were evaluated by seven experts from the UK, France, Germany, Austria and Poland.

\section{References}

Bell, B. S. \& Kozlowski, S. W. J. (2008). Active learning: Effects of core training design elements on self-regulatory processes, learning, and adaptability. Journal of Applied Psychology, 93, 296316.

Graham, C.R. (2004). Blended learning systems: definition, current trends and future directions. In C.J. Bonk and C.R. Graham (Eds). Handbook of Blended Learning: Global Perspective, Local Designs. San Francisco, CA: Pfeiffer Publishing [Retrieved from http://www.click4it.org/images/a/a8/Graham.pdf]

Huggett, C. (2013). The Virtual Training Guidebook. ASTD Press. ISBN: 9781562868611

Keppel, M., Elliot, K., Kennedy, G., Elliot, S. \& Harris, P. (2003). Using authentic patient encounters to engage medical students in a problem-based curriculum. In S. Naidu (ed.), Learning and Teaching with Technology: Principles and Practices (pp. 85-96). London: Kogan Page.

Krug, S. (2006). Don't Make Me Think! A Common Sense Approach to Web Usability (2 ${ }^{\text {nd }}$ Edition). Berkeley, California USA: New Riders.

MacKeogh, K. \& Fox, S. (2009). Strategies for Embedding e-Learning in Traditional Universities:

Drivers and Barriers. Electronic Journal of eLearning, Vol. 7 (No. 2), pp. 147 - 154.Owston, R. (2013). Blended learning policy and implementation: Introduction to the special issue. The Internet and Higher Education, Vol 18, pp. 1-3.

Shepherd, C. (2015). More than Blended Learning. Eastleigh: The More Than Blended Learning Company.

Spanaka, A. \& Kameas, A. (2015)._Training for New E-Learning Role Profiles: the Case of Evirtue Project. In International Conference The Future Of Education, Florence, Italy, 11- 12 June.

Yilmaz, O. (2015). The Effects of 'Live Virtual Classroom' on Students' Achievement and Students' Opinions about 'Live Virtual Classroom' at Distance Education. TOJET: The Turkish Online Journal of Educational Technology, Vol 14 (No. 1), pp. 108-115. Retrieved from: http://www.tojet.net/articles/v14i1/14111.pdf 